\title{
A Review on Flexural Behavior of RCC Beams Made with Geopolymer Concrete
}

\author{
Dr. T. Srinivas ${ }^{1}, S . V$. Srinidhi ${ }^{2}$ and Dr. N.V. Ramana $\mathrm{Rao}^{3}$ \\ ${ }^{1}$ Professor, Department of Civil Engineering, GRIET, Hyderabad, India \\ ${ }^{2}$ M. Tech Structural Engineering Student, GRIET, Hyderabad, India \\ ${ }^{3}$ Professor, Department of Civil Engineering, JNTUH, Hyderabad, India
}

\begin{abstract}
In the process of production of concrete, the emission of carbon dioxide has become a lifethreatening issue and a major drawback towards sustainable development, as there is need to reduce and control this carbon dioxide. It is therefore essential to find a substitute greener material to the existing OPC concrete. Since its significant minor carbon footprint and with usage of industrial by-products, which includes fly ash and ground granulated blast-furnace slag in geopolymer concrete is recognized as a sustainable substitutes. Fly ash is well-off in silicate and alumina, hence it reacts with alkaline solution to generate alumina silicate gel that binds the aggregate to manufacture a good quality concrete. Literature on the flexural behavior of geopolymer concrete (GPC) beams have been studied and compared with the reference concrete beams of the respective grade. From the literature, It has been observed that the development of flexural cracks are relatively less in geopolymer RCC beams compared to conventional beams, the failure occurred in the beams was in flexural mode and the cracks are generated from the tension zone to the compression zone and also the compressive strength greater than before due to decrease in porosity, as the fineness of fly ash enhanced.
\end{abstract}

\footnotetext{
${ }^{1}$ Corresponding Author Email: srinu.tummala@gmail.com
} 


\section{INTRODUCTION:}

The order of cement is rising with the raise of population and the consequent boost in the use of concrete as a construction material. "OPC has been traditionally used as the binding agent in concrete, about one ton of carbon dioxide is emitted into the atmosphere in the production of one ton of cement and the present world is looking for alternative environmentally friendly binders to help reduce the increasing trend of global warming and climate change". In view of the severe effect of carbon dioxide on the atmosphere and the constant escalation of industrialization and urbanization, "there is a need to impart the building industry away from its intense dependence on Portland cement by using alternative binder systems". The options, "which has attracted attention as alternate binders are, fly-ash (At present, India produces approximately 180 million tons of fly ash), and slag as first alternative which are industrial byproducts, and the second alternative as geopolymer binders, is an emerging area of technology, Davidovits first proposed that an alkaline liquid could be used to react with the silicon $(\mathrm{Si})$ and aluminum $(\mathrm{Al})$ in a source material of geological origin or in by-product materials such as fly ash and rice husk ash to produce cementitious binders".

\section{LITERATURE REVIEW:}

M. Ratna srinivas et al. [1] "This paper shows the results on tentativestudy done on reinforced geopolymer concrete beams to know the flexural behavior, the alkaline activator solution is prepared by sodium hydroxide $\mathrm{NaOH}$ and sodium silicate $\mathrm{Na} 2 \mathrm{SiO} 3$ in 1:2.5 ratio". The, "flexural behavior of the beams is examined with different molars of $\mathrm{NaOH}$ solution, the GPC beams are compared with conventional reinforced concrete beam of M40 grade concrete, the type of curing adopted in the experimental study is ambient, the size of beam is $1000 \mathrm{~mm} \times 150 \mathrm{~mm} \times 150$ mm". This, "experimental study gives a clear conclusion on the flexural behavior of conventional reinforced concrete beam and reinforced geopolymer concrete beam made with GGBS".

- The strength of GPC is higher than the OPC.

- The load deflection behavior of the GPC is more than the OPC beams.

- The failure occurred was in the beams in flexural mode. The cracks aregenerated from the tension zone to the compression zone.

N. Sai kiran, Y. et al. [2], "This study describes the experimental investigation on reinforced gpc slabs using GGBS, the aim is to compare the flexural behaviour of geopolymer concrete slab with the conventional concrete of grade M40, the slab dimension is taken as $1000 \mathrm{~mm} \times 1000 \mathrm{~mm} \times 60 \mathrm{~mm}$, the various molarities of $\mathrm{NaOH}$ used in this study were $8 \mathrm{M}, 10 \mathrm{M}, 12 \mathrm{M}, 14 \mathrm{M}$ and $16 \mathrm{M}$ ". The slabs are casted and cured in ambient curing. All slabs are tested on the loading frame and load Vs deflection results are observed. The results showed that GPC slabs have higher strength and less deflection than the conventional concrete slab.

- The load Vs deflection behaviour of Geopolymer concrete slabs are higher than the OPC slab.

- The load carrying capacity of GPC slabs will increase in increase of molarity.

- In higher molarity GPC slabs, the deflection is decreasing when increase in molarity.

Tatsuya Koumoto [3], "Studied the method for production and strength diagnosis of geopolymers considering the chemical composition of fly ash or slags". As per many studies, "factors affecting the compressive strength include the chemical composition of solids, fineness of materials, the ratio of solution $(\mathrm{NaOH}+$ sodium silicate) to solid, the ratio of $\mathrm{NaOH}$ to sodium silicate, the curing time, the curing temperature, the molarity of $\mathrm{NaOH}$ ". In this study, "the six kinds of geopolymer materials, two each of Fly ash, Slag 1 (steel factory slags), Slag 2 (garbage melting furnace slags), were the starting geopolymer materials, and ten mixtures of two each of fly ash and fly ash, fly ash and Slag 1,fly ash and Slag 2, and Slag 1 and Slag 2 , were prepared as materials with a wide range of chemical compositions". investigational procedure includes building Geopolymer Samples with different molarities of $\mathrm{NaOH}$ and Chemical Compositions of Binders. "The results shows that to produce high compressive strength geopolymer, slags have to be ground as fine as possible, the value of (qu) compessive strength generally becomes the maximum value (qumax) maximum compessive strength when the weight ratio of the mixed solutions of $\mathrm{NaOH}$ and sodium silicate to the binder is 0.4 (wopt, which is the optimum value of $w$ yielding qumax), irrespective of the type of the binder".

Xin Ren and Lianyang Zhang [4], "This paper inspects complete recycling of waste concrete to produce new GPC. Specifically, GPC was produced using waste concrete fines (WCF) and class-F fly ash together with mixed sodium hydroxide $(\mathrm{NaOH})$ and sodium silicate $(\mathrm{Na} 2 \mathrm{SiO} 3)$ solution as the geopolymer binder and waste concrete aggregates (both coarse and fine) as the aggregate". The fine and coarse Recycled Aggrgate and WCF were got by crushing the OPC concrete specimens, which are already tested in the Structures Laboratory at the University of Arizona (UA). "The conclusions can be drawn as The RA-based GPC at $\mathrm{C} / \mathrm{A}$ is 0.29 has longer initial setting time and lower UCS than that at C/A is 0.22 ., The RA-based GPC at $10 \mathrm{NaOH}$ concentration has shorter initial setting time and higher UCS than that at $14 \mathrm{NaOH}$ 
concentration. The higher curing temperature of $35^{\circ} \mathrm{C}$ favors the geopolymerization process and leads to higher strength of the GPC than the room curing temperature at $23^{\circ} \mathrm{C}$ ". Both the $\mathrm{WCF}$ and RA from waste concrete crushing can beused to produce GPC with decent mechanical properties.

Xin Ren et al. [5], "This paper studies the interfacial transition zone (ITZ) between geopolymer binder (GP) and recycled aggregate (RA), since RA consists of uncovered stone surfaces and the attached paste/mortar from the original ordinary Portland cementconcrete, both the ITZ between GP and natural aggregate and that between GP and residual OPC paste/mortar (ROPM) were studied, 4-point bending tests were done to measure the bond strength, the water to solid (W/S) ratio has an important effect on the bond strength of the different ITZs.,higher W/S ratio decreases the bond strength of the GP-based ITZs, the GP-RA ITZ shows higher strength than the GP-NA, OPC- NA and OPCRA ITZs, implying the great potential to use RA to produce geopolymer concrete".

Vinu P et al. [7], "The aim of this investigational study carried out is to know the flexural strength of hardened gpc elements reinforced with different types of wire meshes in which the gpc is made using GGBS and Fly ash in Equal proportions as the Cementacious materials and sodium hydroxide and sodium silicate as the alkaline activators". The elements such as slabs and beams are casted using the Geopolymer concrete and different wire meshes keeping the size of the slab as $700 \mathrm{~mm} \times 150 \mathrm{~mm} \times 30 \mathrm{~mm}$. The beams are made of size $700 \mathrm{~mm} \times 150 \mathrm{~mm} \times 150 \mathrm{~mm}$.

- At 7 days of sun light curing the compressive strength exceeds the target compressive strength. "The compressive strength increases substantially when curing period increases from 7 to 14 days, hence a curing period of 7 to 14 days is sufficient to achieve the target strength".

- The flexural strength increases with the increase in number of layers for both square woven metal mesh and expanded hexagonal metal mesh.

Paulo H. R. Borges et al. [8], "This paper employs the Andreasen particle packing method, commonly used for ceramic materials, to improve the geopolymer constructions studied on the development of microconcretes".

\section{limitations were investigated}

- Results have shown that the "Andreasen method may be used to change the rheology and, therefore, develop different geopolymer mixes".

- "In the particular case of the development of geopolymer floor tiles, the best formulation is the one with a solution to solid rate of 1.4 , Andreasen packing factor of 0.235 , and quartz aggregate".

Kunal Kupwade-Patil [6], "This study reports the findings of an experimental investigation for alkali silica reaction (ASR) between reactive aggregates and the geopolymer matrix, specimens were prepared using one Class C and two Class F fly ash stockpiles, the specimens were prepared as per ASTM C490 using reactive aggregates known to initiate ASR reaction (ASTM 2001a), the results of the expansion test, performed as per ASTM C1260 (2001b), for mortar bar specimens immersed in $1 \mathrm{M} \mathrm{NaOH}$ solution at $80^{\circ} \mathrm{C}$, OPC concrete showed higher average enlargement, by a factor of six, compared to GPC specimens following a 90-day exposure to1 $\mathrm{M} \mathrm{NaOH}$ solution at $80^{\circ} \mathrm{C}$, OPC specimens made with sandstone ,quartz, and limestone aggregates exceeded the permissible thresh-old $(0.1 \%)$ for expansion specified by ASTM C1260 (2001b), be-cause these aggregates were prone to ASR". Geopolymer Concrete specimens did not go beyond the ASTM threshold for extension of next 90-days $\mathrm{NaOH}$ exposure stage. "Visual observation of the OPC specimens identified leaching and visual cracks, neither of which was observed in the GPC specimens".

C. Antony Jeyasehar et al. [9]. "The mechanical properties of geopolymer concrete such as compressive strength, split tensile strength and flexural strength have been found out and compared with that of ordinary cement concrete". Five beams of size $125 \mathrm{x}$ $250 \times 3200 \mathrm{~mm}$ were casted and tested. "Out of this five beams, one beam is influence beam with normal cement concrete and the remaining four are geopolymer concrete beams with Alkali -Activator Solution / Fly ash ratio 0.40, 0.45, 0.50, 0.55 and equivalent compressive strength".

- Geopolymer Concrete will be used for structural applications by using class F fly ash.

- The strength of Geopolymer Concrete raised with enhance in Alkali -Activator Solution / fly ash ratio up to 0.5

- As the molarity of $\mathrm{NaOH}$ from $8 \mathrm{M}$ to $16 \mathrm{M}$ increased, the strength of Geopolymer Concrete will be enhanced.

Muhammad M Rahman and Prabir K Sarker [10], This paper presents the behavior of gpc columns under combined axial load and biaxial bending. "Twelve reinforced geopolymer concrete slender columns were tested at different combination of biaxial load eccentricities, the compressive strength of concrete varied from 37 to $63 \mathrm{MPa}$ and the reinforcement ratio was $1.47 \%$ or $2.95 \%$ ". Change was not observed in look of the columns and the cylinders behind contact to altering exterior atmosphere under direct sun and rain over a period of one year. "The failure behavior of the 
columns was similar to that of Ordinary Portland cement (OPC) concrete columns under biaxial loading, strengths of the columns were calculated by using the well-known Bresler's load reciprocal formula and the current Australian Standard for OPC concrete".

From optical inspection, no alter in look was observed in the columns and cylinders behind straight contact to sun and rain in altering weather circumstances for more than one year. "This showed the soundness of geopolymer concrete as a structural material in varying weather conditions, the general load-deflection and failure behaviors of the columns were similar to those usually exhibited by OPC concrete columns with biaxial bending".

Fei Jin et al. [11], the quality of MgO-GGBS mixes is influenced by the reactivity of the $\mathrm{MgO}$. "Extremely reactive $\mathrm{MgOs}$ (reactivity $<30 \mathrm{~s}$ ) brought about higher early quality, however the most significant multi day quality was accomplished by those $\mathrm{MgOs}$ with reactivity around $30-100 \mathrm{~s}$, at the point when the reactivity is too low, the inactive hydration of $\mathrm{MgO}$ will be negative to the concrete suitability in the long term".

\section{MATERIALS AND MIX PROPORTION:}

Fly ash class f [IS:3812(part-1)].Ordinary Portland cement 53[IS:8112]. Coarse aggregate [IS:383 table 2].Fine aggregate [IS:383 table 2].Chemical admixtures [IS:9103].sodium hydroxide pellets, alkaline activator is sodium hydroxide solution, GGBS, Water.

Fly Ash: As per ASTM c-618, there are two types of classes a) class $\mathrm{F}$, is generated by burning bituminous coal which contains calcium less than $10 \%$ b) class $C$, is generated by burning sub-bituminous coal which contains excess calcium (10\%-40\%), due to higher calcium content class c fly ash participate in both cementitious and pozzolanic reaction.

Chemical Characteristics of Indian Fly Ash (low lime fly ash): The fly ash has higher concentration of silicon dioxide and aluminum oxide and lower contents of ferric oxide, as fly ash cannot react with water, which leads to longer life of concrete structure. Delay in heat of hydration helps in reduction in thermal cracks in concrete in turn improves microstructure and rheology.

Code Provisions: Indian Standard IS:3812 (part-1) of 2013 specification for pulverized fuel ash and IS:10262 for mix design .

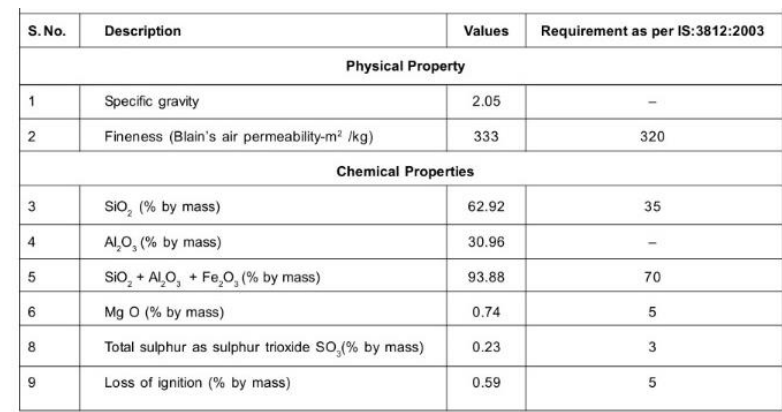

Fig 1. Physical and chemical properties of fly ash.

NaoH: Sodium hydroxide, too known as lye and caustic soda, which is an inorganic compound with the formula $\mathrm{NaOH}$. "It is a white solid ionic compound consisting of sodium cations $\mathrm{Na}+$ and hydroxide anions $\mathrm{OH}-$, sodium hydroxide is a highly caustic base and alkali that decomposes proteins at ordinary ambient temperatures and may cause severe chemical burns. It is highly soluble in water, and readily absorbs moisture and carbon dioxide from the air, it forms a series of hydrates $\mathrm{NaOH} \cdot \mathrm{nH} 2 \mathrm{O}$ ". The monohydrate $\mathrm{NaOH} \cdot \mathrm{H} 2 \mathrm{O}$ crystallizes from water solutions between 12.3 and $61.8{ }^{\circ} \mathrm{C}$. "The commercially available sodium hydroxide is often this monohydrate, and published data may refer to it instead of the anhydrous compound". Sodium hydroxide is used in various cement mix plasticizers. "This helps homogenize cement mixes, preventing segregation of sands and cement, decreases the amount of water required in a mix and increases workability of the cement product, be it mortar, render or concrete".

Ground-granulated blast-furnace slag (GGBS or GGBFS) is obtained by quenching molten iron slag (a by-product of iron and steel-making) from a blast furnace in water or steam, to produce a glassy, granular product that is then dried and ground into a fine powder. "The typical chemical compositions of GGBS are Calcium Oxide: $40 \%$,Silica: 35\%,Alumina: $13 \%$,Magnesia: $8 \%$, the physical properties of slag vary and depend on the method of cooling the slag, the typical physical properties of GGBS are as follows: Color: Off white, Specific Gravity: 9,Bulk Density: $1200 \mathrm{~kg} / \mathrm{m} 3$,Specific Surface Area: 400 to $600 \mathrm{~m} 2 / \mathrm{kg}$ ".

3.7 MIX PROPORTION (G30) (According to IS:10262) The mix proportion is calculated according to Indian Standards IS:10262. Grade of concrete = G30, assumed standard deviation $=5.0$ (according to table 1 of is 10262)

\section{Step:1 Target Mean Strength}

$$
\begin{gathered}
f_{m}=f_{c k}+1.65 S \\
30+1.65(5.0) \\
f_{m}=38.25 N \backslash \mathrm{mm}^{2}
\end{gathered}
$$

Step:2 wlc RatioAssume water cement ratio as 0.45 Aggregate size $=20 \mathrm{~mm}$ (table 2 of is 10262)

Maximum water content $=186 \mathrm{~kg}$ (table 2 of is 10262) 
Step:3 Water content Assuming slump value to be $100 \mathrm{~mm}$ corresponding increment in water is $6 \%$ and decreasing up to $30 \%$ for using superplasticizer

$$
\begin{array}{ll}
\text { - } & 186+\left(\frac{6}{100}\right) \times 186=197.16 \mathrm{~kg} \\
\text { - } & 197.16 \times 0.30=138.021 \mathrm{~kg}
\end{array}
$$

\section{Step:4 Cement Content}

- $\quad$ Cement content $=360 \mathrm{~kg}$

- $f l y a s h=0.85 \times 360=306 \mathrm{~kg}$

- $G g b s=0.15 \times 360=54 \mathrm{~kg}$

\section{Step:5 Volume of Coarse Aggregate and Fine} Aggregate (table 3 IS:10262)From table 3 of IS: 10262 clauses $4.4, \mathrm{~A}-7$ and B-7Nominal size of aggregate for zone II is 0.62 for $20 \mathrm{~mm}$ aggregate*This volume of aggregate is for wlc ratio $0.5^{*} 0.5$ $0.4=0.1$ For every change of $w \mid c$ ratio 0.05 , the Coarse aggregate volume will change by 0.01 vice versatherefore, $0.1 \times \frac{0.01}{0.05}=0.02$ Total volume of aggregate $=0.62+0.02=0.64$, Coarse aggregate $=$ 0.64 , Fine aggregate $=1-\mathrm{CA}=0.36$

\section{Step:6 Mass of Admixture}

a) Volume of concrete $=1 \mathrm{~m}^{3}$

b) Volume of (cement) $=\frac{360}{3.15} \times \frac{1}{1000}=$ $0.114 \mathrm{~m}^{3}$

c) Volume of water $=0.138 \mathrm{~m}^{3}$

\section{EXPERIMENTAL INVESTIGATION:}

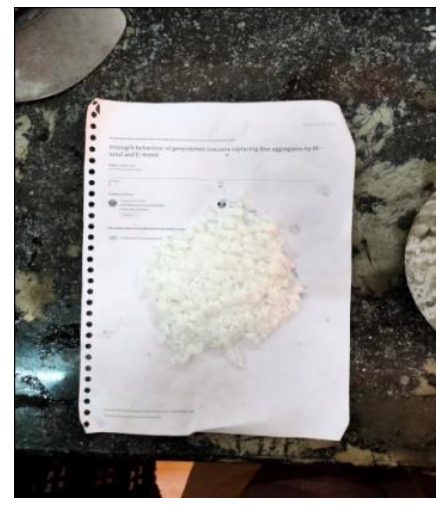

$\mathrm{NaOH}$ pellets

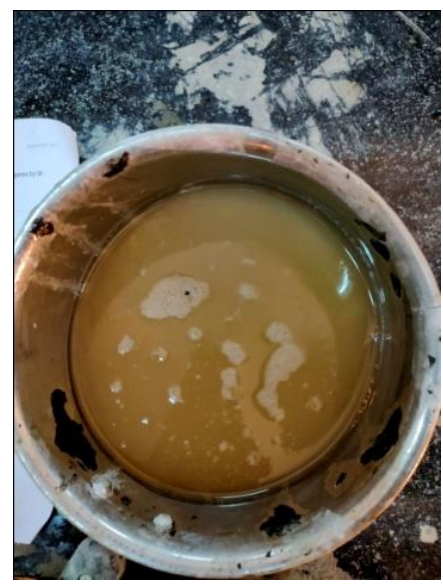

Alkaline activator a) Volume ofadmixture: $2 \%$ of (cement) $=6.9$ $\mathrm{kg}=\frac{6.9}{1.145} \times \frac{1}{1000}=0.006026$

b) Volume of aggregate $=(\mathrm{a}-(\mathrm{b}+\mathrm{c}+\mathrm{d})=(1-$ $(0.114+0.138+0.006026)=0.741 \mathrm{~m}^{3}$

Mass of coarse aggregate $=\mathrm{e}^{\times \mathrm{vol}}$ of $\mathrm{ca} \times$ sp gravity of ca

$$
=0.741 \times 0.64 \times 2.74=1308 \mathrm{~kg}
$$

Mass of fine aggregate $=\mathrm{e} \times \mathrm{vol}$ of $\mathrm{fa} \times$ sp gravity of fa

$$
=0.741 \times 0.36 \times 2.67=717 \mathrm{~kg}
$$

Table 1. Final mass of ingredients

\begin{tabular}{|l|l|}
\hline Ingredient & Mass $\left(\mathbf{k g} / \mathbf{m}^{\mathbf{3}}\right)$ \\
\hline Fly ash + GGBS & 360 \\
\hline Water & 138 \\
\hline Coarse aggregate & 1308 \\
\hline Fine aggregate & 717 \\
\hline Admixture & 6.9 \\
\hline wlc ratio & 0.45 \\
\hline
\end{tabular}

Therefore, the mix proportion for $0.45 \mathrm{w} / \mathrm{c}(\mathrm{G} 30)$ is 1:2:3.6:0.45

Fly ash + GGBS $=1$, Fine aggregate $=2$, Coarse aggregate $=3.6$

Water content $=0.45$.

Sodium hydroxide pellets are to be mixed in the most commonly used alkaline activator is sodium hydroxide solution. Most of the literature suggested that the solution and the pellets to be mixed prior to 24 hours before casting but in our investigation, we understood that 30 minutes is sufficient before casting (based on trail and error basis) if the solution is kept upon 30 minutes there was an increase in water content i.e., after 30 minutes for every delayed 10 to 15 minutes we have to add more amount of water to get the suitable workability that has to be placed in molds. Utmost care has to be taken while mixing the pellets into $\mathrm{NaOH}$ solution by stirring it continuously as the pellets will be settled at bottom if left still, as solution reacts with pellets and produce great amount of heat and vapors so wearing gloves is important. The solution then is transferred after 30 minutes to pan mixer where all the other ingredients like coarse aggregate, fine aggregate, flyash, GGBS, are placed before hand, then transferred to molds. After setting the GPC cubes are demoulded and a batch ( 6 cubes) is kept in oven for 24 hours at $60^{\circ} \mathrm{C}$.

After 24 hours it is kept aside to cool down for one day and this period is called resting period. The other batch ( 6 cubes) are kept for ambient curing, Then the cubes are subjected to compression on 3,7,14 days and the results are tabulated and comparison is made between oven cured, ambient cured and conventional concrete. 


\section{Conclusions:}

From the literature, it has been observed that

- The developments of flexural cracks are relatively less in geopolymer RCC beams compared to conventional RCC beams.

- The failure occurred in the beams was in flexural mode and the cracks are generated from the tension zone to the compression zone

- The compressive strength is greater than before due to decrease in porosity, as the fineness of fly ash is more in case of geopolymer concrete.

- The mix proportions, which are used to manufacture geopolymer and conventional concrete, are same.

\section{References:}

1. M. Ratna srinivas ${ }^{1}$, Y. Himath $\mathrm{Kumar}^{2}$, B. Sarath Chandra Kumar", "Studies on Flexural Behavior of Geopolymer Concrete Beams with GGBS ”, (IJRTE) ISSN: 2277-3878, Volume-7, Issue-6C2, April (2019).

2. N. Sai kiran ${ }^{1}$, Y. Himath $\mathrm{Kumar}^{2}$, B. Sarath Chandra Kumar" , "Experimental Investigation on Reinforced Geopolymer Concrete Slabs", (IJRTE) ISSN: 2277-3878, Volume-7, Issue6C2, April (2019).

3. Tatsuya Koumoto,Ph.D. "Production of High Compressive Strength Geopolymers Considering Fly Ash or Slag Chemical Composition", ASCE journal. (2019).

4. Xin Ren and Lianyang Zhang, M.ASCE, "Experimental Study of Geopolymer ConcreteProduced from Waste Concrete", 10.1061/(ASCE)MT.1943-5533.0002750.C (2019).

5. Xin Ren and Lianyang Zhang, "Experimental study of interfacial transition zones between geopolymer binder and recycled aggregate",X. Ren, L. Zhang / Construction and Building Materials 167 749-756 (2018).

6. Kunal Kupwade-Patil, Ph.D.; and Erez N. Allouche, Ph.D., "Impact of Alkali Silica Reactio on Fly Ash-Based Geopolymer
Concrete " ,X. Ren, L. Zhang / Construction and Building Materials 167 749-756. (2018).

7. Anchula Nagarjuna, T. Suresh Kumar, B.Yogeswara Reddy, M.Udaykiran, International Journal of Innovative Technology and Exploring Engineering, Vol. 8 no. 11, pp: 640-645, (2019)

8. Paulo H. R. Borges; Lucas F. Fonseca; Vitor A. Nunes; Tulio H. Panzera; and Carolina C. Martuscelli, "Andreasen Particle PackingMethod on the Development of Geopolymer Concrete for Civil Engineering", DOI: $\quad 10.1061 /(A S C E) \quad$ MT.19435533.0000838. American Society of Civil Engineers.( 2014).

9. C. Antony Jeyasehar, G. Saravanan, M. Salahuddin and S.Thirugnanasambandam. "Development of fly ash based geopolymer precast concrete elements", ASIAN JOURNAL OF CIVIL ENGINEERING (BHRC) VOL. 14, NO. 4,605-615. (2013).

10. Naspuri Arun Raju, T. Suresh Kumar, International Journal of Innovative Technology and Exploring Engineering, Vol. 8 no. 11, pp: 3860-3864, (2019)

11. Fei Jin,KaiGu, Adel Abdollahzadeh, and Abir Al-Tabbaa Ph.D. "Effects of Different Reactive MgOs on the Hydration of MgOActivated GGBS Paste". 27(7): B4014001.(2015).

12. Srinivasa Reddy, V., Seshagiri Rao, M.V., Shrihari, S, "Appraisal of processing techniques for recycled aggregates in concrete", IJEAT, 8 (6), pp. 1661-1665, (2019).

13. Satyanarayana, G.V.V., Saikiran, C.H, " Effect on mechanical properties of M35 grade concrete by partial replacement of fine aggregate with copper slag", IJITEE, 8 (12), pp 3759-3762.

14. Sateesh, N., Sampath Rao, P., Ravishanker, D.V., Satyanarayana, K., "Effect of Moisture on GFRP Composite Materials", Materials Today: Proceedings, 2 (4-5), pp. 2902-2908, (2015).

15. Reddy, V.M., Manikanta, S, "Mechanical properties of fibre reinforced self compacting concrete using rice husk ash", IJRTE, 8 (3), pp. 6412-6415, (2019). 